
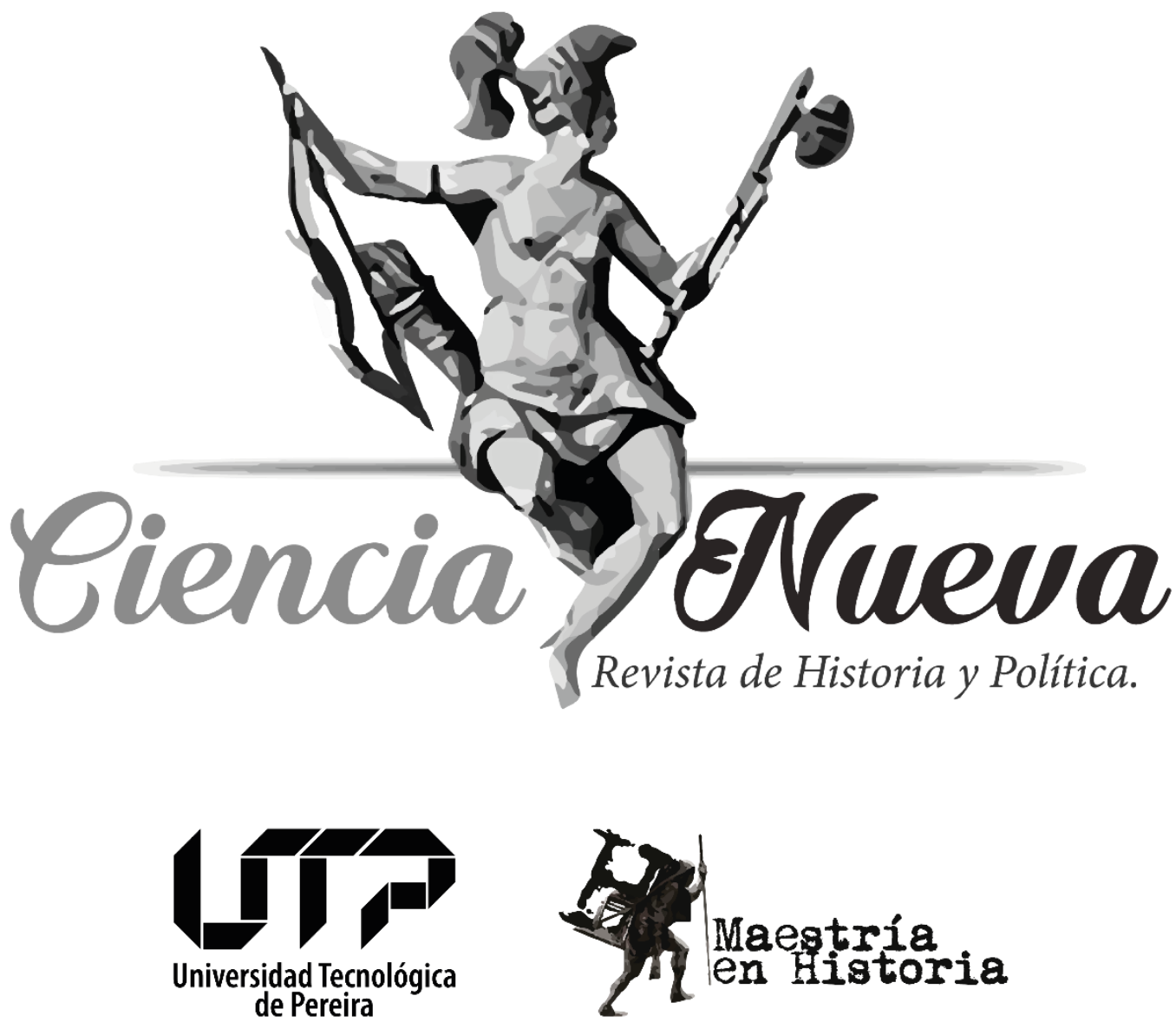

CIENCIAS POLÍTICAS

EL LIBERALISMO DE IGNACIO V. ESPINOSA THE LIBERALISM OF IGNACIO V. ESPINOSA Gonzalo Cataño pp. 69-81

Vol. 4 Núm. 1 | Enero-Junio de 2020

Pereira, Colombia 


\section{EL LIBERALISMO DE IGNACIO V. ESPINOSA*}

THE LIBERALISM OF IGNACIO V. ESPINOSA

Gonzalo Cataño**

anomia45@outlook.com

ORCID: http://orcid.org/0000-0001-7415-0608

$\begin{array}{cl}\text { Recibido: } & \text { 14 de septiembre de } 2019 . \\ \text { Revisado: } & 18 \text { de septiembre de } 2019 . \\ \text { Aceptado: } & 25 \text { de octubre de } 2019 . \\ \text { Publicado: } & 04 \text { de septiembre de } 2020 .\end{array}$

\section{Resumen}

Espinosa no fue, en verdad, un pensador original. Sus amigos, colegas y estudiantes lo exaltaron, pero en ello siempre hubo más cariño y devoción por la persona que reflexión sobre sus logros intelectuales. Fue un divulgador piadoso y poco docto del legado de Herbert Spencer en el salón de clase y en las planas de periódicos y revistas. Murió joven y muy joven publicó sus trabajos. Se lo recuerda en los anales nacionales de la Colombia fin de siècle por su tesis de grado El matrimonio (1889), por la Filosofía experimental, extracto de las doctrinas psicológicas de Herbert Spencer (1891), por su conferencia El positivismo (1893) y por las Bases positivas del liberalismo (1895), su libro más representativo.

Palabras clave: Liberalismo, historia intelectual, Colombia, siglo XIX.

\begin{abstract}
Espinosa was not, an original thinker indeed. His friends, colleagues and students praised him, but there was always more affection and devotion for the person than reflection on his intellectual achievements. He was a pious and unlearned popularizer of Herbert Spencer's legacy in the classroom and on the pages of newspapers and magazines. He died young and very young published his works. $\mathrm{He}$ is remembered in the national annals of Colombia fin de siècle for his graduate thesis "El Matrimonio" (1889), Filosofía experimental, extracto de las doctrinas psicológicas de Herbert Spencer (1891), for his lecture El Positivismo (1893) and for the Las Bases Positivas del Liberalismo (1895), his most representative book.
\end{abstract}

Keywords: Liberalism, intellectual history, Colombia, 19th century.

\footnotetext{
* Este documento respeta las directrices y normas dispuestas en la Declaración de Ética de Publicación de Ciencia Nueva, Revista de Historia y Política. Esta declaración puede consultarse en la página web de la revista: http://revistas.utp.edu.co/index.php/historia

** Profesor investigador de la Universidad Externado de Colombia, sociólogo de la Universidad Nacional de Colombia, Master of Arts de la Universidad de Stanford y doctor en Sociología Jurídica e Instituciones Políticas de la Universidad Externado de Colombia.
} 
Los conservadores han empleado a la Iglesia como instrumento de dominación. Ya [el general] Manuel Briceño, en son de excusa o defensa contra el cargo de fanáticos, que se hacía a los de su partido, contestó un día, con su habitual franqueza, que "los conservadores habían tenido que empuñar la bandera religiosa porque los liberales se lo habían cogido todo: la libertad, el progreso, la democracia; en suma, todas las grandes ideas y todas las grandes palabras"200.

$\mathrm{E}$ n un pasaje del Plan agrícola, libro de Luis Ospina Vásquez poco frecuentado por los investigadores, el analista de la economía nacional registró la pobreza del pensamiento político colombiano. Para ilustrarlo, aludió de pasada al autor de las Bases positivas del liberalismo, afirmando que, dado el febril entusiasmo por lo nacional, quizá un historiador del futuro opte por exaltar "el pequeño catecismo positivista de Ignacio $\mathrm{V}$. Espinosa, como una exposición de las ideas de la corriente positivista de nuestro país, fruto de largas cavilaciones..." ${ }^{201}$. Encontraba el texto liviano, ligero y pobre a pesar de que en su libro mayor Industria y protección en Colombia lo había usado para ilustrar las afinidades de la ideología liberal con las políticas librecambistas ${ }^{202}$.

Espinosa no fue, en verdad, un pensador original. Sus amigos, colegas y estudiantes lo exaltaron, pero en ello siempre hubo más cariño y devoción por la persona que reflexión sobre sus logros intelectuales. Fue un divulgador piadoso y poco docto del legado de Herbert Spencer en el salón de clase y en las planas de periódicos y revistas. Murió joven y muy joven publicó sus trabajos. Se lo recuerda en los anales nacionales de la Colombia fin de siècle por su tesis de grado El matrimonio (1889)203, por la Filosofía experimental, extracto de las doctrinas psicológicas de Herbert Spencer (1891) ${ }^{204}$, por su conferencia El positivismo $(1893)^{205}$ y por las Bases positivas del liberalismo $(1895)^{206}$, su libro más representativo. A ellos se deben sumar, La reorganización (1898) ${ }^{207}$, un complemento de las Bases dirigido a llamar la atención sobre los peligros de la dirección despótica (personalista) de los partidos políticos, y la útil Jurisprudencia de la Corte Suprema de Justicia de $1896^{208}$, redactada en compañía del jurista Juan B. Quintero C. — futuro profesor de Derecho Civil y de Práctica Forense del Externado_-, que registra las innovaciones de la casación ${ }^{209}$. Y no solo esto. Un

\footnotetext{
200 Palabras del dirigente conservador Manuel Briceño recogidas por Rafael Uribe Uribe en sus Documentos militares y políticos (Bogotá: Imp. de Vapor, 1904), 463.

${ }^{201}$ Luis Ospina Vásquez, Plan agrícola (Medellín: Granamérica, 1963), 89.

${ }^{202}$ Luis Ospina Vásquez, Industria y protección en Colombia (Medellín: Editorial Santafé, 1955), 297.

${ }^{203}$ Ignacio V. Espinosa, “El matrimonio", Revista Judicial, Bogotá, serie 12, n. ${ }^{\text {os }}$ 4-7 (1889), en Tesis del primer Externado, 1886-1895, comp. por J. C. Rodríguez Gómez (Bogotá: Universidad Externado de Colombia, 2011), 51-59.

${ }^{204}$ Ignacio V. Espinosa, Filosofía experimental, extracto de las doctrinas psicológicas de Herbert Spencer. (Bogotá: Imprenta de Lleras, 1891).

${ }^{205}$ Ignacio V. Espinosa, El positivismo (Bogotá: Imprenta de Torres, 1893).

${ }^{206}$ Ignacio V. Espinosa, Bases positivas del liberalismo, con un prefacio de Miguel Triana (Bogotá: Imprenta de Torres Amaya, 1895; 2a ed. (Bogotá: Imprenta de Samper Matiz,1896); $3^{\text {a }}$ ed. (Bogotá: Imprenta de "Gaceta Republicana", 1911).

${ }^{207}$ Ignacio V. Espinosa, La reorganización (Bogotá: Papelería de Samper Matiz, 1898).

${ }^{208}$ Ignacio V. Espinosa y Juan B. Quintero C., Jurisprudencia de la Corte Suprema de Justicia (Bogotá: Imp. de la Luz, 1896).

${ }^{209}$ La posibilidad de enmendar los errores de los jueces. El recurso de casación, acto de revocar una sentencia, se instituyó en el país en 1886. Como lo observaron Quintero y Espinosa, Jurisprudencia de la Corte..., VI, "casar sentencias [del latín cassare, nulo] permite estudiar las dificultades que en la práctica vayan presentando las leyes". Tiene como fin aclarar las normas, reemplazar las disposiciones oscuras, expulsar los vicios de forma
} 
compañero de estudios del Rosario, Ambrosio Robayo, recordó en una ocasión la existencia de un folleto de crítica literaria, de una Ética que no alcanzó a publicar y de un panfleto sobre El fetiquismo, colombianismo que se usaba en la época para señalar los peligros de la veneración excesiva, fetichista, de una creencia ${ }^{210}$. Hasta el momento no se ha encontrado rastro alguno de estos textos.

\section{I}

Poco se sabe de la vida de Ignacio V. Espinosa. Su existencia transcurre en relativo mutismo a lo largo de la era radical (1863-1886), que tanto amó, defendió y ensalzó. Nació en 1860 y murió en la madrugada del siglo XX, en 1903. Adelantó su enseñanza primaria y secundaria en los años setenta y a comienzos de los ochenta trabajó en la escuela nocturna para obreros de Bogotá y en varias escuelas normales de gran auge por aquellos días. Inició sus estudios universitarios en el Colegio Mayor de Nuestra Señora del Rosario y luego se trasladó al Externado de Colombia de Nicolás Pinzón Warlosten fundado en 1886, el mismo año de la Constitución de signo conservador que tuteló la vida política de los colombianos por más de una centuria. Nada se sabe de sus padres, pero todo parece indicar que venía de una familia modesta, y que su instrucción prosperó al lado de una tenacidad de la voluntad acompañada de la generosidad de amigos y familiares. Durante su estadía en el Rosario dirigió el semanario El Estudio, hoja donde emprendió sus primeras experiencias literarias. Se graduó en el Externado en 1887, cuando se afirmaba la Regeneración y los liberales perdían el poder que habían disfrutado por más de dos decenios.

Sus mejores años fueron los de la primera mitad del decenio de 1890. Por aquellos días ocupó la vicerrectoría del Externado, enseñó varias materias y difundió sus escritos académicos y políticos más atendidos. Allí tuvo a su cargo las asignaturas de Psicología y Ortografía y Corrección de Voces, materia esta última de gran provecho para los estudiantes que redactaban sus tesis de grado. En 1890 estuvo por unos meses al frente del periódico liberal El Demócrata y esporádicamente ejerció la profesión para complementar sus ingresos docentes. Como buen pedagogo era afable con los jóvenes y amigo de la conversación abierta y sostenida. Tuvo fama de filósofo, de pensador recóndito que pocos entendían. Sus Bases circulaban en los medios intelectuales y un bromista llegó a decir que ni él mismo las comprendía $^{211}$. No hay noticia de su eventual participación en los levantamientos liberales

\footnotetext{
y unificar la jurisprudencia - las sentencias y resoluciones - para proteger la seguridad jurídica. Desde una perspectiva histórica, la revisión de los juicios por un tribunal superior da lugar, con los años, a la formación de una doctrina endógena de gran significado para el desenvolvimiento jurídico interno de un Estado.

Durante el siglo XX y los comienzo del XXI se afinaron estos objetivos. En la actualidad la casación no busca tanto la nulidad como el "romper", "quebrar" y adecuar las sentencias. El Código general del proceso de 2012 la define en su artículo 333, como el recurso extraordinario que busca "defender la unidad e integridad del ordenamiento jurídico, lograr la eficacia de los instrumentos internacionales suscritos por Colombia en el derecho interno, proteger los derechos constitucionales, controlar la legalidad de los fallos, unificar la jurisprudencia nacional y reparar los agravios irrogados a las partes con ocasión de la providencia recurrida".

${ }^{210}$ Ambrosio Robayo, "Ignacio V. Espinosa", en El Liberal Ilustrado, tomo 4, n. $1392-19$ (Bogotá, junio 12 de 1915), 292 .

${ }^{211}$ Luis E. Nieto Caballero, Escritos escogidos (Bogotá: Banco Popular, 1984), vol. I, 25. Quizá el crítico se refería no tanto a las Bases como creía Nieto Caballero, sino a su enigmática - arcana - conferencia sobre el positivismo. El lector que se adentra a sus páginas con un conocimiento mínimo del legado de Comte sospecha que Espinosa no sabía muy bien de qué estaba hablando. Lo mismo ocurre con pasajes enteros de $L a$ reorganización, donde la reiterada evocación de un Spencer atropellado y mal digerido hace ininteligible el texto. Ante estas asperezas, el profesor de Lengua Inglesa y de Derecho de Gentes del Externado, Alejo de la Torre, no se ahorró sus chanzas: "Ignacio ha leído mucho a Spencer, pero no lo entiende". Ver Eduardo
} 
de 1895 o de 1899, la guerra de los Mil Días, revueltas en las que participaron y perdieron la vida varios de sus estudiantes. ¿Se casó, tuvo hijos, murió en soledad? Nada se sabe al respecto.

Después de 1895, cuando el Externado de Colombia cerró las puertas a causa de la temprana muerte de su fundador, rector y propietario, Pinzón Warlosten (1859-1895), su existencia entró en una opacidad de la que no parece haber salido. Pinzón Warlosten, casi de su misma edad, fue su mecenas, profesor y amigo por cerca de diez años, y con su desaparición quedó en el vacío, sin un asiento institucional estable. Ya no hubo para Espinosa ingresos seguros, discípulos aplicados y lectores dedicados. Parece haber terminado el siglo en angustiosas y precarias labores profesionales. Su camarada Robayo, muy dado al arrebato, escribió que en los últimos años estuvo consagrado al ejercicio del foro en el ramo penal, campo en el cual "su palabra resonó muchas veces en pro de los infortunados, y en más de una ocasión su verbo inspirado [...] logró arrancar víctimas al cadalso"212. En 1898 acompañó a su amigo el ingeniero, historiador y etnógrafo Miguel Triana al Ecuador en una misión académica para apoyar las reformas educativas del presidente Eloy Alfaro, el líder de la "revolución liberal de Ecuador". La misión fue un fracaso. Al llegar a Quito se encontró que no había recursos para emprender las tareas para las cuales había sido contratado. De todas formas, tuvo oportunidad, la única en su vida, de visitar un país extranjero ${ }^{213}$. Murió el 24 de agosto de 1903 cuando rozaba los cuarenta y tres años y el país se aprestaba a asumir el siglo XX después de los infortunios de la guerra de los tres años y la pérdida de Panamá, el territorio que unía la nación con el estratégico subcontinente centroamericano. Se ignora la causa de su fallecimiento. Los obituarios de la época eran muy dados al furor retórico, dejando de lado el registro de las experiencias más significativas del finado. Solo sus amigos más cercanos tuvieron conocimiento del nombre que se escondía detrás de la solitaria $\mathrm{V}$ acompañada de un inofensivo punto seguido que siempre antepuso a su apellido ${ }^{214}$.

\section{II}

Las Bases positivas del liberalismo alcanzaron un relativo éxito. "Estudio que tuvo cierta boga en su tiempo y aún después"215. Espinosa las publicó en 1895 en la Imprenta de Torres Amaya, con un prólogo de Miguel Triana, y al año siguiente las volvió a sacar en las prensas de la Samper Matriz. En 1911, cuando ya había muerto, los talleres de la Gaceta Republicana, el diario de Enrique Olaya Herrera fundado en 1909, las pusieron de nuevo en circulación para consumo de estudiantes y entusiastas de las ideas liberales.

Las Bases, un "ensayo" según sus propias palabras, presentan una organización en parágrafos muy similar a la seguida por los libros de Spencer. Contiene 56 parágrafos ordenados en 14 capítulos que abordan un tema particular: la libertad, la propiedad, el sufragio, el Estado, los partidos políticos... La prosa de Espinosa es enfática y taxativa,

Rodríguez Piñeres, Diez años de política liberal, 1892-1902 (Bogotá: Librería Colombiana, 1945), 33.

212 Robayo, "Ignacio V. Espinosa", 292

213 Carl H. Langebaek y Natalia Robledo Escobar, Utopías ajenas: evolucionismo, indios e indigenistas (Bogotá: Universidad de los Andes, 2014), 82, 97 y 147-157.

${ }^{214}$ Para fugaces apuntes biográficos de Espinosa, ver el texto citado de Robayo; el ensayo de Nelson J. Chacón, "El intelectual y las ciencias: Ignacio Espinosa y el positivismo", Memoria y Sociedad 10, n." 21 (julio-diciembre de 2008): 69-84, y el volumen de Juan C. Rodríguez Gómez, La luz no se extingue: historia del primer Externado, 1886-1895 (Bogotá: Universidad Externado de Colombia, 2018), passim. La entrada "Espinosa, Ignacio V.” del Diccionario biográfico y bibliográfico de Joaquín Ospina (Bogotá: Cromos, 1927), a cargo del mencionado Robayo, es solo un resumen de su texto de 1915.

215 Ospina Vásquez, Industria y protección..., 297. 
elemental y escueta, sin matices; es teóricamente pobre y empíricamente limitada. Apenas hay ejemplos que respalden sus generalizaciones. El autor no desarrolla los temas, los enuncia; no duda, afirma. Sus párrafos tienden a ser dictámenes lacrados, aforísticos y refraneros, y sus explicaciones siguen a menudo la senda del silogismo. Dos ejemplos.

Lo que impide el ejercicio correcto de [las facultades humanas], produce la destrucción del individuo y de la especie, y todo lo que lo favorece hace el bienestar del hombre y de la humanidad. Ejercitar las facultades humanas es, pues, un hecho bueno, así como es malo impedir su ejercicio $(\S 1)^{216}$.

$\mathrm{Si}$ el correcto ejercicio de las facultades es bueno, y si ese ejercicio constituye el derecho, es claro que todos los derechos son buenos. Ahora bien, si el ejercicio del derecho es la libertad, es evidente que ella a nadie perjudica, y, por el contrario, a todos aprovecha $(\S 1)$.

En las Bases no abundan las citas ni las referencias a autores y obras, pero, como era de esperar, su ídolo Herbert Spencer aparece una y otra vez seguido de lejos por el norteamericano James Otis, los franceses Édouard Laboulaye y André Chevrillon y los ingleses James Mackintosh, Thomas Buckle y Lord Macaulay. Menciona a Newton para ilustrar el papel de la ley como enunciado de una generalización. Y solo eso, lo demás es la prosa sentenciosa de Espinosa que avanza libre de estorbos. Por parte alguna define la noción de "bases positivas" que da lugar al título del ensayo, pero su empleo sugiere que la utiliza para describir los rasgos esenciales del pensamiento liberal. Por "positivo" parece entender lo cierto, efectivo y verdadero sin descuidar lo útil. Ello le sirve para exaltar los preceptos de adelanto y mejora del individuo y de la sociedad, voz esta última de cadencia colectiva que usó para referirse a un número amplio de personas unidas por un sentimiento de solidaridad. Estos preceptos contrastaban con la corriente conservadora, doctrina y campo de acción que en el texto ocupa el papel de lo "negativo", esto es, de lo ajeno a la mudanza y al progreso.

\section{III}

A pesar de las limitaciones, Espinosa exploró en su obra asuntos de interés para su época y la nuestra. Su punto focal es la libertad, el poder de obrar sin cortapisas que considera la base del bienestar de las sociedades y del engrandecimiento de las naciones. A su juicio, los pueblos libres son los más civilizados. Los hombres que no han logrado superar el absolutismo, los pueblos primitivos, andan errantes por la selva o favorecen las naciones inclinadas al delito y a formar individuos inútiles para el trabajo, la ciencia y la creación. Para él el liberalismo es el régimen de nuestros días, la ideología que se funde con los gobiernos de la sociedad moderna. En las organizaciones cerradas del pasado no hay cabida para las ideas liberales a no ser el de las organizaciones idílicas exaltadas por los libros sagrados o las sagas de tiempos remotos, que jamás estaremos seguros de que hayan existido.

A la libertad unió una segunda conquista del liberalismo: la igualdad. En las sociedades abiertas, el derecho rige la conducta de los miembros. No hay allí privilegios para el que delinque; la norma ampara y juzga al rey y al siervo, al jefe de la nación y al vasallo más modesto. Pero la igualdad de Espinosa era ante la ley, no ante la estratificación social. Era una misma regla para medir personas diferentes. Jamás buscó subvertir las distinciones de clase o las diferencias entre ricos y pobres.

¿Cómo querer que el legislador por medio de leyes establezca que el ignorante es igual que el sabio, el pordiosero igual al potentado, el gañán de los campos igual que al caballero de las ciudades, y el

\footnotetext{
${ }^{216}$ A lo largo de este ensayo, las referencias al libro de Espinosa se registran por el número del parágrafo mas no de la página. Esto facilita la consulta de las citas en cualesquiera de las ediciones de las Bases.
} 
remendón de zapatero al abogado, al médico al comerciante?” (§ 8).

¡Imposible! Para Espinosa la desigualdad era un estado natural, no una condición socialmente creada, pero veía en el derecho un mecanismo de defensa de los desheredados y de moderación de la disparidad ${ }^{217}$. En el futuro lejano, sin embargo, la misma evolución natural de las cosas abriría el camino de la igualdad social. Para él la edad de oro del género humano, su utopía, no estaba en el pasado, sino en el porvenir, en la perfección del orden social a la que tienden de manera inexorable las sociedades humanas.

Sin duda, el fin a que tiende la humanidad es a una nivelación completa. Así parece dejarlo comprender la ley de la selección [natural]. La supervivencia de los más aptos acabará por no dejar sino los absolutamente mejores. Entonces no habrá nobles ni plebeyos, pobres ni ricos [y] el genio será patrimonio común de aquella humanidad feliz [...] Mientras tanto tenemos que someternos, si queremos ser relativamente dichosos, a la inflexible realidad de las cosas. Debemos reconocer las diferencias que existen hoy entre los hombres, dejar que las leyes naturales se cumplan, y trabajar porque la legislación de los pueblos no sea obstáculo a este cumplimiento (\$7).

A lo anterior se sumaba el derecho de propiedad, esto es, la facultad que tienen los hombres de disponer de lo suyo. ¿Cómo podría sostenerse un individuo a quien se le arrebata la fuente de subsistencia adquirida con su trabajo?

Donde impera el liberalismo, reina la lucha, el debate y la controversia. Aquí era donde brotaban los partidos políticos, las fuerzas colectivas de la estática y la dinámica, de la quietud y el cambio en la sociedad. Cualquiera que sea su nombre, solo hay dos partidos: el liberal y el conservador, el que empuja hacia adelante y el que conserva lo establecido. Toda organización política de nuestros días los requiere. Su acceso al poder se obtiene mediante la alternabilidad, la circulación de las colectividades en el gobierno, proceso que se legitima con el sufragio, jornada electoral que fortalece la democracia. En medio de esta tensión surge otro valor muy apreciado por los liberales, la tolerancia, el respeto a las opiniones y prácticas ajenas. Aquí la diferencia con los conservadores era clara y directa. Por doctrina, los conservadores eran "ciegos defensores de la fe y enemigos irreconciliables de la libertad de pensar” (§ 23). Al compendiar estas ideas estampó su tipo ideal de liberalismo:

[El liberalismo incluye], de un modo absoluto, la inviolabilidad de la vida humana, la libertad individual, la seguridad personal, la expresión del pensamiento, la igualdad, la asociación, la locomoción [desplazamiento libre de las personas], la inviolabilidad del domicilio, la libertad de industria, la libertad de instrucción, la libertad de conciencia, la propiedad, en una palabra, los derechos del hombre $(\S 6)$.

IV

Para alcanzar una mayor conciencia de los aspectos positivos del liberalismo en el país, Espinosa recurrió a la tipología spenceriana, hoy bastante olvidada, de sociedades militares versus sociedades industriales ${ }^{218}$. Las militares son aquellas donde el aparato de gobierno está en manos de un autócrata protegido por el ejército y demás organismos de coerción.

\footnotetext{
${ }^{217}$ Esto era una manifestación más de lo apuntado por su amigo Robayo. En el foro —recordó- la palabra de Espinosa resonó siempre en pro de los infortunados y en ocasiones sus afanes salvaron más de una víctima del patíbulo. Robayo, "Ignacio V. Espinosa", 292

${ }^{218}$ Desarrollada en los capítulos 17 y 18 de las "Political institutions", la extensa monografía de Spencer que ocupa la parte quinta de The principles of sociology (New York: Appleton, 1877-1896). En castellano se pueden consultar por separado en H. Spencer, Instituciones políticas (Madrid: La España Moderna, s.f.), vol. II (la misma edición que Espinosa tuvo a mano para su exposición).
} 
Deriva su nombre de la semejanza de su organización con el ordenamiento de una milicia. Es una sociedad jerárquica, centralizada, guerrera y autoritaria. El mando viene de arriba y se va ramificando a medida que se desciende en los peldaños del organismo social. Bajo el régimen militar la soberanía reside en el jefe, cuya persona se confunde con el Estado y se presenta como dueño y amo de la nación. Al lado del poder absoluto del rey marcha la autoridad de sus generales sobre sus subordinados, y el de estos últimos sobre los hombres que están por debajo de ellos. En la Francia medieval había un monarca y tras él una jerarquía de señores feudales, sus vasallos, que a su vez eran soberanos de los siervos de la gleba, la población que trabajaba y residía en sus heredades. No hay allí respeto por la propiedad privada. Esta puede ser arrebatada o confiscada a voluntad del superior o del agresor externo. A todo esto, estaba unida una cultura de sumisión, sentimientos e ideas que tejían las relaciones de subordinación entre el individuo y el Estado, entre la persona y el regente de turno. En la población impera la creencia de que existe para beneficio de la sociedad y no para provecho y bienestar de sus integrantes. Están allí para salvar la patria y el orden, el país y el terruño. La guerra - la agresión y el ataque, el amparo y la protección — rondan la vida cotidiana de los reinos. La nación es algo parecido a un ejército en reposo. Aquí la obediencia es virtud y la resistencia un crimen que se paga con la vida, la reclusión, el despojo o la expulsión del país. La institución religiosa favorece este entramado. Es severa, rígida y absorbente. La Iglesia está en manos del Estado al cual sirve y nutre y del que muchas veces es un mero apéndice. Con frecuencia el sumo sacerdote es también el jefe de gobierno. El ejemplo más cercano al tipo ideal de sociedad militar lo encontraba Spencer en el despotismo oriental encarnado en el Egipto de los faraones. Allí todo era restricción y anulación de la persona humana. Algo semejante sucedía con el Perú de los Incas donde dioses y reyes se confundían en deidad y omnipotencia.

Las sociedades industriales son la antípoda de las militares. Son colaborativas, individualistas y democráticas. Viven en paz y respetan el derecho de propiedad. Lo industrial está asociado al trabajo y a la producción de bienes y a la habilidad y destreza diligencia y vivacidad - de hacer cosas libremente. La cooperación es voluntaria, jamás presionada o constreñida. Las relaciones entre jefes y subordinados, patronos y obreros, compradores y vendedores, profesiones liberales y clientes se hacen a voluntad. No hay estorbos al comercio, a la iniciativa privada o a la circulación de personas de un lugar a otro. Los rangos y las ocupaciones son abiertas al talento y no hay impedimentos de status para su acceso. Las regulaciones surgen de acuerdos (contratos), entre los individuos y entre estos y las autoridades. El Estado existe para beneficio y seguridad de los miembros y se accede a sus dignidades mediante el sufragio. Se promueven los partidos, las guildas y toda clase de organizaciones privadas.

A juicio de Spencer, en sus días no existía una sociedad industrial propiamente dicha. Apenas surgían. Los Estados que más se acercaban eran las ciudades hanseáticas, los Países Bajos y, ante todo, Inglaterra y Estados Unidos. España, Alemania, Italia y Francia estaban todavía lejos ordenamiento industrial. El estatismo asfixiaba la vida de sus miembros y la iniciativa de sus grupos. Rusia era una incursión en territorio europeo de los desolados despotismos de las extensiones asiáticas. Grecia había sido una amable sociedad industrial en la época de la Atenas clásica, en el siglo de Pericles, pero después cayó en absolutismos de diverso tipo. Los países de América Latina, "en revolución perpetua”, eran tierra abonada para el militarismo y el autoritarismo, de mandos sin contrapesos ${ }^{219}$.

${ }^{219}$ Herbert Spencer, Principios de sociología (Madrid, Saturnino Calleja, 1883), vol. II, 127. 
La caracterización de Spencer debía entenderse como tipos ideales, como construcciones intelectuales para el estudio de los casos concretos. La realidad brindaba una compleja mezcla de uno y otro tipo. Era tarea de los investigadores evaluar el peso de cada uno de ellos cuando se adentraba al examen de una organización social particular. Además, su aparición y desenvolvimiento, su elevación y desplome, no debía entenderse como un proceso lineal y forzoso de lo militar a lo industrial como lo sugerían la experiencia de Occidente o las tipologías sociedad tradicional versus sociedad moderna. Una nación industrial bien podía mutarse en militar a causa de una invasión extranjera, de una revolución comunista, de un golpe de Estado o de una dictadura aupada por grupos extremistas desprendidos de las Fuerzas Armadas. En estos casos se entronizaba la arbitrariedad y se afianzaban las distintas modalidades de centralismo, atropello y nepotismo propias de las tiranías.

\section{V}

Espinosa se sirvió de esta tipología para estudiar el caso colombiano ${ }^{220}$. Observó que en la Colombia de fin de siglo imperaban los rasgos militares con escasa o nula presencia de las de tipo industrial, que solo se manifestaron de manera muy tenue en la época radical. No hubo allí tiempo para su consolidación. La Regeneración, un gobierno absolutista que apenas pasaba "de la época salvaje al período bárbaro" 221 , los momentos más tempranos y violentos de las sociedades militares, se perpetuaba en el Estado. Allí el estado de sitio era permanente y el partido de oposición, el liberal, conocía el destierro, la prisión y el confinamiento. La Iglesia, intolerante, se unía al partido de gobierno y regía el contenido de la enseñanza primaria, secundaria y universitaria. En nombre de la paz se suprimía la prensa, se entorpecía la controversia y se constreñía la libertad del docente en la cátedra. No se respetaba la propiedad. Prevalecían las expropiaciones, los privilegios y los monopolios, y "los más salvajes atentados contra las personas quedaban impunes, si eran llevados a término por los que tienen mando o llevan la investidura militar" (§ 45). Los ejércitos en liza reclutaban por la fuerza a los jóvenes de ciudades, pueblos y veredas, y cuando las facciones en contienda negociaban sus frágiles armisticios, los despedían a su antojo con sus cuerpos lacerados y su espíritu trastornado.

Era tarea del liberalismo transformar esta situación de sujeción, atraso y miseria. Las naciones más adelantadas - Suiza, Inglaterra y Estados Unidos - mostraban que era posible alcanzar el industrialismo, la sociedad "del hombre verdaderamente civilizado". Pero este paso se tomaba su tiempo. Era insensato pretender que las naciones saltaran de la noche a la mañana del régimen coercitivo al de la cooperación voluntaria. La evolución en la naturaleza y en la sociedad no admitía saltos. Había que preparar la población para que dejara atrás siglos de sujeción y entrara sin obstáculos a la sociedad de los gobiernos libres.

Recurriendo al más crudo darwinismo spenceriano, sostuvo que la supervivencia de los más aptos es el resultado de la instrucción forzosa que la naturaleza le brinda a los seres $\operatorname{vivos}^{222}$. Mediante el placer y el dolor les comunica lo que les es afín y lo que les perjudica

\footnotetext{
${ }^{220}$ Ya la había usado con anterioridad su alumno Ricardo Hinestrosa Daza en su tesis de grado Los partidos políticos (Bogotá: Imprenta de Echavarría Hermanos, 1892). Ver Gonzalo Cataño, "Un estudio sobre los partidos políticos", Revista de Economía Institucional 13, ${ }^{\text {n. }}$ 25, (2011): 362-364.

${ }^{221}$ Espinosa, La reorganización ..., 4.

${ }^{222}$ Se debe señalar que la expresión "selección de los más aptos" (the survival of the fittest) era de Spencer y no de Darwin. Este último era más dado a hablar de selección natural, pero encontraba — según lo apuntó en el tercer capítulo de El origen de las especies - que el enunciado de Spencer era, en ciertos casos más exacto y
} 
para sobrevivir. El reino de lo social no escapa a este proceso: sociedad que no entrenara a sus vástagos desaparecía.

La enseñanza obligatoria es un hecho que se cumple a través de la escala de los organismos y un resultado de la tendencia natural en ellos a vivir y a progresar [... y] si consideramos la sociedad como un todo que se mueve en el sentido del progreso, es claro que la enseñanza obligatoria se presenta como consecuencia de la ley citada $(\S 52$ y $\S 53)$.

Este era el fundamento "científico" de su política escolar. Lo demás era el esfuerzo de los gobiernos por desarrollar la enseñanza primaria para erradicar el analfabetismo a fin de sentar las bases de la "civilización”. Para orientar este proceso de larga duración hacia el estadio industrial había que moldear las instancias que lo hicieran posible y hacerse a las riendas del Estado, la estructura básica de mando en la sociedad. Para Espinosa, el Estado era una institución vaporosa nada fácil de asir justificada en las leyes de una constitución. En él se instala el gobierno, el organismo encargado de administrar los asuntos públicos. Los gobiernos empujan al Estado y lo ponen en acción, y mientras que el Estado es fijo, los gobiernos cambian según los ascensos y caídas de las fuerzas políticas, los partidos.

¿Como romper con el imperio de la sociedad militar en el país? Ante todo, con el libre juego de los partidos que airean la política, el gobierno y el Estado. Unos partidos innovan y otros conservan lo adquirido.

Políticamente hablando la civilización es hoy el resultado del antagonismo de los dos partidos [...] ¿Qué valor tendría el partido conservador sin el liberal que lo obliga a moverse, a sufrir transformaciones y a considerar como suyo lo que el liberalismo ha conquistado? ¿Y qué valdría el partido liberal si los conservadores no lo obligasen a detenerse y a hacer que las naciones experimentasen por algún tiempo el resultado de sus innovaciones, a fin de conservarlas si son útiles, o de olvidarlas si son perjudiciales? [...] El racional antagonismo entre ellos es indispensable para que la acción del gobierno quede en el límite precioso de la justicia [...] La muerte del uno es el aniquilamiento del otro (§17).

Para que todo esto marche se deben cambiar las formas de pensar de la población, ya que "las ideas y los sentimientos son las fuerzas generadoras del crecimiento político" ( $\S$ 55). El oscurantismo es fuente de inercia y apatía y los mismos partidos se fortalecen con la incorporación a sus filas de bases ilustradas conscientes de las ideas que suscitan su adhesión. Y "siendo el liberalismo el partido que representa en el mundo el progreso", nada más natural que cuente entre los principios de su programa el de la enseñanza primaria gratuita, laica y obligatoria ( $\$ 55)$. Sin educación formal no hay adelanto. La sociedad moderna es cultura letrada, sociedad de textos escritos y de cálculos permanentes. La escuela facilita el acceso a las ciencias y a las artes y promueve las habilidades para ponerlas en práctica. Económicamente hablando, los pueblos no se apropian de la nueva sociedad sino cuando sus hijos son capaces de ejercitar los trabajos que el régimen industrial requiere. $\mathrm{Su}$ naturaleza demanda operarios entrenados, trabajadores que sepan leer y escribir, sumar y restar, multiplicar y dividir, atributos que solo se consiguen cuando la educación es patrimonio común de la nación. El ciudadano, el habitante de la ciudad, que no sepa contar el dinero, los días y la hora, o no alcance a comprender los mensajes grabados en los avisos públicos o en los periódicos y revistas del día, está perdido. Nadie se desempeña con holgura en la metrópoli y en el mundo laboral de la gran factoría si carece de los rudimentos del

conveniente y, quizá, más elegante. Darwin era un gran escritor; no en vano El origen ha sido considerado una obra maestra de la literatura inglesa. 
alfabetismo. Las empresas que cuentan con obreros educados son además las más prósperas.

Pero aquí no terminaban las bondades de la instrucción pública. Para Espinosa, sus beneficios se extendían a otros campos de la vida social. La escuela animaba la previsión y el ahorro, frenaba el vicio y el crimen y contribuía al control demográfico. Los hogares analfabetos, la mayoría de la población, contaban en sus días con diez, quince y hasta veinte hijos mal alimentados y peor vestidos propensos a la mendicidad y a la delincuencia. Un entrenamiento adecuado reduciría estas conductas de incuria y desidia, y si la función primordial de todo gobierno era dar seguridad a vida y hacienda de los individuos que integran la nación, el Estado debía mejorar la base formativa de los hombres haciéndolos más prudentes, honrados y responsables de sus actos. La educación del infante anticipa lo que queremos que sea el adulto. Este aprendizaje dejaría atrás el imperio del azote, la mazmorra y el patíbulo como mecanismos de control social tan corrientes en las sociedades de aliento militar.

VI

Este era el escenario de las Bases positivas del liberalismo del empeñoso Ignacio V. Espinosa. La educación popular anunciaba la nueva sociedad y la fundación de escuelas abría el camino para entrar en ella. Para alcanzar su cometido, desalojar la superstición, debía ser laica, esto es, ajena a toda Iglesia y proyecto confesional. A la escuela lo que era de la escuela y a la Iglesia lo que era de la Iglesia; los maestros a la enseñanza y el clero al culto de la divinidad y a la salvación de las almas.

Pero un examen más detenido de las orientaciones de Espinosa dejaba ver sus fisuras. Su tiempo y el que le siguió afrontaba nuevas demandas que apenas tenían cabida en sus marcos de referencia. Su insistencia en la igualdad jurídica llevó a Gerardo Molina, el historiador más acreditado de las ideas liberales en el país, a calificar su postura de "terriblemente anticuada"223. A su juicio, Espinosa veía la sociedad colombiana con quevedos muy estrechos. En sus días, como en los nuestros, la desigualdad no era solo un asunto jurídico, sino también y de manera especial un problema social. Espinosa no lo vio. Pensaba que "la naturaleza ha querido que en el universo predomine la desigualdad" ( $\$ 8$ ). Hubo que esperar a la llegada de las corrientes socialistas, tan odiadas por Espinosa afincado en un individualismo radical - la persona lo es todo, la sociedad es solo un agregado - para testificar la desigualdad como un problema de la estructura social ${ }^{224}$.

Su aproximación a los partidos políticos fue igualmente pobre. Concibió la lucha por el poder como una querella entre liberales y conservadores, entre idearios progresistas y posturas de vigilancia del statu quo. No tuvo sensibilidad para observar el ascenso de nuevos partidos que además del cambio expresaban intereses de clase. Las luchas del influyente Partido Socialdemócrata Alemán era el mejor ejemplo fin de siècle. Sus reclamos mostraban

\footnotetext{
${ }^{223}$ Gerardo Molina, Las ideas liberales en Colombia: 1849-1914 (Bogotá: Universidad Nacional de Colombia, 1970), 175.

224 A Gerardo Molina, un demócrata irreductible, igualmente le molestaba la tendencia de nuestro autor a entregarle la dirección de los partidos a una elite ilustrada. "La dirección de los partidos —escribió Espinosacorresponde a la minoría inteligente". Esa minoría - agregó - no se comunica "con la gran masa, sino que lo hace por medio de las personas superiores a esa masa, pero inferiores en potencia a la minoría" ( ${ }^{20 \S}$ ). Con estas posturas — apuntó Molina_ “el rol de las masas en la historia queda suprimido, lo mismo que su aspiración a tomar parte en la conducción del Estado". Molina, Las ideas liberales...' 176 años después, Espinosa morigeró este elitismo en La reorganización. Allí criticó la creencia de que los miembros de un partido deben obedecer ciegamente las decisiones de los jefes de la organización.
} 
que los partidos, además de intereses ideales (concepciones de la sociedad), también expresaban intereses materiales (económicos) de las clases populares con deseos de participar en las decisiones del Estado. Con sus demandas las diferencias entre conservadores y liberales fueron desapareciendo y el liberalismo fue perdiendo su perfil crítico y su papel subversivo. Ahora los recién llegados le arrebataban uno de sus réditos ideológicos más queridos que enarbolaba desde los años de la Revolución francesa.

Algo parecido ocurría con la propiedad. Espinosa hablaba de una sociedad de propietarios: de rentistas, artesanos y agricultores. Su corazón parecía inclinarse por los medianos propietarios de la tierra, la población que trabajaba directamente su terruño. Olvidaba, sin embargo, que la propiedad no es conditio sine qua non para vivir. No observó las clases que carecían de ella y que de alguna forma tenían una existencia decorosa: las clases medias urbanas. Eran los funcionarios públicos, los empleados de las casas comerciales, los trabajadores por cuenta propia, los docentes de la enseñanza primaria y secundaria, el suyo y el de sus colegas salidos de la universidad: los ingenieros, los médicos y los abogados. Es verdad que era una categoría reducida en la Colombia de 1890, un grupo cultural tan minúsculo como la cabeza de un alfiler, pero no por ello menos significativo. Hoy en día, con la expansión del sector terciario ha alcanzado una notable presencia en la sociedad. Para sus miembros el concepto de propiedad apenas roza la idea de vivienda, mas no como fuente de sustento. Solo los sectores medios tradicionales — artesanos, tenderos, comerciantes medianos y pequeños propietarios rurales - viven de la explotación de su propiedad, que muchas veces es arriendo y no posesión ${ }^{225}$.

$\mathrm{Su}$ fe en la plena libertad de los negocios, el laissez faire, y en la promoción y aliento de toda organización privada, también porta dificultades. Es cierto que Espinosa criticó acerbamente los monopolios amparados por el Estado - "los monopolios y los privilegios son atentados contra la propiedad", o aún más, "el proteccionismo es toda una teoría contra la propiedad, lo mismo que sus derivados el comunismo y el socialismo" (§ 14) - . Pero no sospechó las consecuencias negativas del crecimiento desmesurado de ciertas asociaciones que terminan por dominar la vida económica y social de una nación hasta convertirse, como la Iglesia, en un Estado dentro del Estado (§ 29). Los norteamericanos todavía recuerdan la jactancia del presidente de una vigorosa y extendida corporación: "lo que es bueno para la General Motors es bueno para Estados Unidos".

Se ha destronado, igualmente, el mito de la educación como factor de paz, seguridad y equidad. Naciones con altos niveles educativos no son igualitarias y se destripan en guerras mundiales o en contiendas internas. La educación formal no mengua de por sí la violencia o la inseguridad. Si su mensaje no encuentra respaldo en las fuentes superiores de poder y decisión -Estados, gobiernos, parlamentos - su labor "humanista" se ve seriamente limitada. La pobreza, los genocidios y los crímenes contra la humanidad no van siempre asociadas a los niveles educativos. Sobrepasan la labor escolar y tienen un origen diferente al de los amables predicados del salón de clases. Son los factores reales de poder, los grupos y las instituciones con capacidad de decisión ${ }^{226}$, los que animan la vida política y sellan el

\footnotetext{
${ }^{225} \mathrm{Al}$ hablar de la propiedad, Espinosa también se olvidó de los sectores que en principio carecen de ella, aquellos que solo cuentan con su fuerza de trabajo. Nada se dice en las Bases sobre los peones, obreros y aprendices de los talleres artesanales, o de las sirvientas, modistas, tejedoras y jornaleras. Esta omisión no era ignorancia. Su alumno Ramón Vanegas Mora había estudiado los asalariados — hombres y mujeres - en la aplaudida tesis de grado del Externado, Estudio sobre nuestra clase obrera (Bogotá: Imprenta de Torres Amaya, 1892).

${ }^{226}$ Ferdinand Lassalle ¿Qué es una Constitución? (Buenos Aires: Siglo XX, 1964), 55 y ss.
} 
rumbo de la nación, no el inerme mensaje de amor, amistad y comprensión del "otro" predicado por maestros y maestras en los planteles escolares. La escuela es colaboradora fecunda de procesos sociales, económicos y políticos, no variable independiente que se baste a sí misma.

\section{VII}

A pesar de que Espinosa deja en el lector la sensación de estar defendiendo un liberalismo viejo salido de una sociedad añeja que hoy es pasado, su texto pone de nuevo en discusión los dones del liberalismo. La libertad, la igualdad, la democracia, el pensamiento libre. Al abordar los peligros de la educación en manos del clero anunció las desdichas de la cultura en las sociedades autoritarias. Tenía claro que "sin libertad la ciencia es estéril y el arte infecundo" y que "los productos de las letras y las artes protegidas por el despotismo son como los expósitos", los niños abandonados en un paraje público. Unos y otros son tan débiles que "avergüenzan a los que les dieron vida" (§ 3). Las lecciones de los países comunistas del siglo XX y la experiencia de las dictaduras de Hitler en Alemania y de Franco en España, constituyen sus mejores ejemplos. Allí se constriñó la cátedra, la filosofía, el arte, la música y las ciencias sociales con resultados funestos para la cultura superior. Espinosa vio esto y lo registró con energía en las Bases positivas del liberalismo para escarnio de las futuras generaciones. Para él toda restricción no consentida por el ciudadano era fuente de opresión o - para decirlo con sus propias palabras de mayor peso analítico - "toda limitación que no sea definida por la capacidad política del ciudadano es tiranía” (§ 35).

\section{Referencias}

Cataño, Gonzalo. "Un estudio sobre los partidos políticos". Revista de Economía Institucional 13, n. ${ }^{\circ} 25$ (2011): 361-373.

Chacón, Nelson J. "El intelectual y las ciencias: Ignacio Espinosa y el positivismo". Memoria y Sociedad 10, n. 21 (julio-diciembre de 2008).

Darwin, Charles. El origen de las especies por medio de la selección natural. Madrid: Calpe, 1921.

Espinosa, Ignacio V. Filosofía experimental, extracto de las doctrinas psicológicas de Herbert Spencer. Bogotá: Imprenta de Lleras, 1891. El positivismo. Bogotá: Imprenta de Torres, 1893. La reorganización. Bogotá: Papelería de Samper Matiz, 1898. Bases positivas del liberalismo. Bogotá: Imprenta de Torres Amaya, 1895. $2^{\mathrm{a}}$ ed. 
Bogotá: Imprenta de Samper Matiz, 1896. 3ª ed. Bogotá: Imprenta de "Gaceta Republicana", 1911.

. "El matrimonio". Revista Judicial, Bogotá, serie 12, n. ${ }^{\text {ss }} 4-7$ (1889). En Tesis del primer Externado, 1886-1895, compilado por J. C. Rodríguez Gómez, 51-59. Bogotá: Universidad Externado de Colombia, 2011.

Espinosa, Ignacio V. y Juan B. Quintero C. Jurisprudencia de la Corte Suprema de Justicia. Bogotá: Imp. de la Luz, 1896.

Hinestrosa Daza, Ricardo. Los partidos políticos. Bogotá: Imprenta de Echavarría Hermanos, 1892.

Langebaek, Carl H. y Natalia Robledo Escobar. Utopías ajenas: evolucionismo, indios e indigenistas. Bogotá: Universidad de los Andes, 2014.

Lassalle, Ferdinand. ¿Qué es una Constitución? Buenos Aires: Siglo XX, 1964.

Molina, Gerardo. Las ideas liberales en Colombia: 1849-1914. Bogotá: Universidad Nacional de Colombia, 1970.

Nieto Caballero, Luis E. Escritos escogidos. Bogotá: Banco Popular, 1984.

Ospina Vásquez, Luis. Industria y protección en Colombia. Medellín: Editorial Santafé, 1955.

- Plan agrícola. Medellín: Granamérica, 1963.

Ospina, Joaquín. Diccionario biográfico y bibliográfico. Bogotá: Cromos, 1927.

Robayo, Ambrosio. "Ignacio V. Espinosa". En El Liberal Ilustrado, tomo 4, n. 1392-19. Bogotá, junio 12 de 1915.

Rodríguez Gómez, Juan C. La luz no se extingue: historia del primer Externado, 1886-1895. Bogotá: Universidad Externado de Colombia, 2018.

Rodríguez Piñeres, Eduardo. Diez años de política liberal, 1892-1902. Bogotá: Librería Colombiana, 1945.

Spencer, Herbert. The principles of sociology. New York: Appleton, 1877-1896. . Instituciones políticas. Madrid: La España Moderna, s.f. . Principios de sociología. Madrid: Saturnino Calleja, 1883.

Uribe Uribe, Rafael. Documentos militares y políticos. Bogotá: Imp. de Vapor, 1904. 
Vanegas Mora, Ramón. Estudio sobre nuestra clase obrera. Bogotá: Imprenta de Torres Amaya, 1892. 